\title{
To study the impact of lifestyle over menstrual pattern in medical students
}

\author{
Sangeeta S Desai ${ }^{1}$, Vasudha D Sawant ${ }^{2 *}$, Payal Gohil ${ }^{3}$, Manjiri Desai ${ }^{4}$ \\ ${ }^{\mathbf{1}}$ Associate Professor, ${ }^{2} \mathrm{HOD},{ }^{3}$ Resident, ${ }^{4}$ Assistant Professor, ${ }^{\mathbf{1 - 3}}$ Dept. of Obstetrics and Gynaecology, ${ }^{\mathbf{4}}$ Dept. of Community Medicine, D Y \\ Patil Medical College, Kolhapur, Maharashtra, India
}

*Corresponding Author: Vasudha D Sawant

Email: vasudhaswnt@gmail.com

Received: $8^{\text {th }}$ February, 2019

Accepted: $18^{\text {th }}$ March, 2019

\begin{abstract}
Introduction: Stress is an integral part of medical profession. Sedentary lifestyle has a great impact over many health problems. Reproductive health is one of the contributing factor to overall female health. Reproductive health problems have significant role in woman's total life. These problems also increases stress further \& have major effect over psychosocial health. All are intermingled with each other. The purpose of the study is to see the effect of life style over the menstrual pattern \& so on to the reproductive health.

Materials and Methods: This is a cross sectional study conducted in DR. D. Y. Patil Hospital in January 2019 in Female Medical Students $(n=159)$. They were provided with prevail dated questionnaire which included various aspects of lifestyle and menstrual pattern. Data collected was analysed analysed by using SPSS (version 23.0).

Results: In present study $82 \%$ \& $81.7 \%$ of students were facing stress \& dysmennorhoea respectively. Hypothyrodism percentage is $21.3 \%$ i.e. quite high. All participants were doing yoga but frequency of doing being varied. All were junk food eater but percentage of occasional eaters was only $18 \%$. In present study, $76 \%$ participants were having premenstrual symptoms.

Conclusion: There is no significant association of life style over menstrual disorders except dysmennorhoea. In present study incidence of PCO and Hypothyroidism was quite high which is worry some. Both have got significant association with junk food and stress. Yoga is found to improve blood flow during menstruation. Still to come on concrete opinion we need more studies from India including other field also.
\end{abstract}

Keywords: Menstrual pattern, Junk food, Yoga, stress.

\section{Introduction}

Menstruation is the integral part of women's life in reproductive age group. Though its physiological phenomenon, it may not be so easy to go through it. Menstrual disorders may be in the form of dysmenorrhoea, polymennorhea, menorrhagia, irregular and scanty menses and premenstrual symptoms. Prevalence of menstrual disorders related health issue are regarded as high as $87 \%^{1}$ of them dysmenorrhoea is commonest with prevalence of up to $90 \% .^{5-7}$ Severe dysmenorrhoea curtails their physical activity. It may be spasmodic after onset of menses or congestive prior to menses.

Normal menstruation is regular cyclical bleeding occuring after every 21 to 45 days for 3-5 days with an average loss of $20-80 \mathrm{ml}^{4}$ If blood loss occurs $>80 \mathrm{ml}$ in amount and in duration $>7$ days, it is called menorrhagia. Passage of clots is also taken as s/o menorrhagia. Hypomennorhea is scanty menses $<2$ days. If duration is $<21$ days, it is called polymennorhea and if it is $>35$ days, it is called oligomennorhea. Premenstrual Syndrome comprises of psychological ill health leading to anxiety, depression, irritability, mastalgia which affects behavioural factors. The hormones which regulate cyclical endometrial changes are based on ovarian condition. Disorders of menstruation can be caused by emotional stress, significant weight fluctuation, endocrine disorders (hypo/hyperthyroidism), disorders of hypothalamo-pituitary ovarian axis and other metabolic disorders. ${ }^{14}$

Various studies has been conducted to find out that dysmenorrhoea is the most prevalent menstrual problem during adolescence. ${ }^{5,7}$

Singh A, Sood M has shown that dysmenorrhoea and premenstrual symptoms are most commonly related to absence from academic curriculum and there is limitation for daily activities. ${ }^{2,3}$ Menstrual patterns can be affected by many factors including age, ethnicity, family history, smoking, physical activity and dietary habits. ${ }^{8}$ Association between stress and menstrual disorders has been documented. ${ }^{10}$ Medical students are reported to be under constant academic stress due to vast curriculum ${ }^{13}$ resulting in menstrual disorders in female medical students $^{11,12}$

The associated medical conditions like hypothyroidism and PCO if diagnosed and treated early, many menstrual disorders can be corrected. But there are other variables like BMI, dietary habits, physical exercises and psychological stress which can affect the menstrual pattern. These factors need to be studied which may modify the risk of developing menstrual irregularities.

\section{Materials and Methods}

The present study was conducted at Dr. D.Y. Patil Hospital, Kolhapur, Maharashtra, India. This is cross sectional study conducted in undergraduate female medical students in the month of January 2019. About 159 undergraduate female students willingly enrolled in the study. They were provided with a prevalidated questionnaire which included various aspects of lifestyle and menstrual pattern. The students filled the questionnaire without disclosing their names. The filled 
questionnaire was collected immediately to prevent the bias. The collected data was analysed by using SPSS (version 23.0). Association between all qualitative variables is observed by using chi-square test of association $(p<0.05)$ is considered statistically significant at $5 \%$ level of significance.

The objectives of the present study are: 1) To determine average age of menarche. 2) To study pattern of menstrual cycle in medical students. 3) To study prevalence and types of menstrual disorders. 4) To find out association of menstrual disorders with life style and stress.

Menstruation is an integral part of every woman in her reproductive life irrespective of fields they are working. Women have to stay away from her home to achieve the goals in her life. It may be professional education, jobs and business. She has to do multitasking including managing her home \& outside activities. Medical profession is highly stressful. The society looks towards this profession with great expectation and demands. To pursue a medical degree, student have to study hard \& so they are at high risk for stress (2). This stress ultimately affects their life \& so on to their menstrual pattern. Hypothalamo-pituitary axis has to be properly functioning for physiology of menstruation. This may get affected by all the biological variables. These factors can be modified.

The impact of lifestyle and physical activities like exercise, yoga, academic stress on menstrual pattern have been studied in various parts of countries including India. In present study, we tried to find the association of various lifestyle patterns, behavioural patterns, diet, physical activities and environmental impact and heavy burden of academic strees on their menstrual pattern.

\section{Observations and Results}

Table 1: Demographic Characteristics of the patients

\begin{tabular}{|c|c|c|}
\hline Characteristics & Percentage & No. of Subjects (n=159) \\
\hline \multicolumn{3}{|c|}{ Age group of medical students } \\
\hline$<22$ yrs & 2.13 & 03 \\
\hline $22-25 y r s$ & 63.52 & 101 \\
\hline$>25 y r s$ & 34.35 & 55 \\
\hline \multicolumn{3}{|c|}{ Address } \\
\hline Rural & 12.57 & 139 \\
\hline Urban & 87.43 & 21 \\
\hline Married & Marital Status & 138 \\
\hline Unmarried & 13.2 & \\
\hline
\end{tabular}

The above table shows demographic data. Average age of participants is $24.68+-2.07$ years. Out of 159 students. ( $87 \%$ ) were from urban area. $13 \%$ of them were married.

Table 2: Lifestyle chartacteristics of the participants

\begin{tabular}{|c|c|c|}
\hline Characters & Percentage & No. Of subjects $(n=159)$ \\
\hline \multicolumn{3}{|c|}{ Food habits } \\
\hline Mix & 52.8 & 84 \\
\hline Non veg & 20.1 & 32 \\
\hline Veg & 27.1 & 43 \\
\hline \multicolumn{3}{|c|}{ Frequency of eating junk food } \\
\hline $1 / \mathrm{wk}$ & 59 & 94 \\
\hline $2-3 / w k$ & 23 & 37 \\
\hline Occasional & 18 & 28 \\
\hline \multicolumn{3}{|c|}{ Dieting } \\
\hline No & 74.8 & 119 \\
\hline Yes & 25.2 & 40 \\
\hline \multicolumn{3}{|c|}{ Yoga } \\
\hline Daily & 16.3 & 26 \\
\hline Occasional & 58.4 & 93 \\
\hline Weekly & 25.3 & 40 \\
\hline \multicolumn{3}{|c|}{ Stress } \\
\hline
\end{tabular}




\begin{tabular}{|c|c|c|}
\hline No & 14.4 & 23 \\
\hline Yes & 85.6 & 136 \\
\hline \multicolumn{2}{|c|}{ Addiction } \\
\hline Tea & 34 & 54 \\
\hline Coffee & 20 & 32 \\
\hline Chocolate & 66 & 73 \\
\hline
\end{tabular}

The above table elaborates lifestyle characteristics of the participants. $27 \%$ were pure vegetarian. All participants were doing yoga but frequency varied. More than half i.e. $58.4 \%$ were doing it irregularly and occasionally. High percentage (85.5\%) was experiencing stress of various types. About $25.1 \%$ were on diet. Approximately 59\% were eating junk food, 2-3 times/week which is quite high. There was no association of yoga with amount of menstrual cycle irregularity..

Table 3: Menstrual pattern among medical students

\begin{tabular}{|c|c|c|}
\hline Characters & Percentage & No. Of subjects $(n=159)$ \\
\hline \multicolumn{3}{|c|}{ Age of menarche } \\
\hline $11 \mathrm{yrs}$ & 23 & 37 \\
\hline $12 \mathrm{yrs}$ & 41 & 65 \\
\hline $13 \mathrm{yrs}$ & 32 & 50 \\
\hline $14 \mathrm{yrs}$ & 4 & 7 \\
\hline \multicolumn{3}{|c|}{ Duration of flow } \\
\hline$<2$ days & 8 & 13 \\
\hline 2-5 days & 81 & 129 \\
\hline 5-7 days & 11 & 17 \\
\hline \multicolumn{3}{|l|}{ Amount of flow } \\
\hline$<2$ pads/day & 74.8 & 119 \\
\hline 2-4 pads/day & 23.9 & 38 \\
\hline 4 pads/day & 1.25 & 2 \\
\hline \multicolumn{3}{|l|}{ Cycle regularity } \\
\hline Irregular & 36 & 58 \\
\hline Regular & 64 & 101 \\
\hline \multicolumn{3}{|l|}{ Dysmennorhoea } \\
\hline Yes & 82 & 130 \\
\hline No & 18 & 29 \\
\hline \multicolumn{3}{|l|}{ Pms } \\
\hline No & 24 & 38 \\
\hline Yes & 76 & 121 \\
\hline
\end{tabular}

Above table shows that the average age of menarche was (12.1+/_1.22). About $81 \%$ of participants had normal duration of flow. Approximately $74.8 \%$ participants were changing less than 2 pads per day. Only $36 \%$ participants showed irregular cycles. Dysmenorrhoea and premenstrual symptoms were the complaints in $82 \%$ and $76 \%$ respectively

Table 4: Medical disorders among medical students

\begin{tabular}{|c|c|c|}
\hline Characters & Percentage & No. of subjects (n=159) \\
\hline \multicolumn{3}{|c|}{ Family history of menstrual disorders } \\
\hline No & 66.1 & 105 \\
\hline Yes & 33.9 & 54 \\
\hline No & History of hypothyroidism \\
\hline Yes & 78.7 & 125 \\
\hline \multicolumn{3}{|c|}{21.3} \\
\hline No & History of pcos \\
\hline Yes & 63.5 & 101 \\
\hline Investigations & 36.5 & 58 \\
\hline HB & 72.3 & 115 \\
\hline USG & 38.3 & 61 \\
\hline TFT & 32.7 & 52 \\
\hline
\end{tabular}


The above table shows about $21.3 \%$ had hypothyroidism for which $32.7 \%$ had undergone thyroid function test. The incidence of PCOS was about $36.4 \%$ for which $38.3 \%$ were investigated for ultrasonography

Table 5: Association between lifestyle \& menstrual disorder

\begin{tabular}{|c|c|c|c|c|c|c|c|c|c|}
\hline Lifestyle & \multicolumn{2}{|c|}{ Cycle regularity } & \multicolumn{3}{|c|}{ Duration of bleeding } & \multicolumn{2}{c|}{$\begin{array}{c}\text { Amount of bleeding } \\
\text { Dysmennorhoea }\end{array}$} \\
\hline & Regular & Irregular & $<2$ days & $2-5$ days & $>5$ days & $\begin{array}{c}<4 \\
\text { pads/day }\end{array}$ & $\begin{array}{c}>4 \\
\text { pads/day }\end{array}$ & Yes & No \\
\hline Junk food & $123(77.3 \%)$ & $36(22.6 \%)$ & $12(7.4 \%)$ & $129(81.1 \%)$ & $17(10.6 \%)$ & $119(74.8 \%)$ & $40(25.1 \%)$ & $130(81.7 \%)$ & $29(18.2 \%)$ \\
\hline & $\mathrm{P}=0.58$ & & $\mathrm{P}=0.40$ & & & $\mathrm{P}=0.031 * *$ & & $\mathrm{P}=0.92$ & \\
\hline Yoga & $123(77.3 \%)$ & $35(22 \%)$ & $12(7.4 \%)$ & $129(81.1 \%)$ & $17(10.6 \%)$ & $119(74.8 \%)$ & $40(25.1 \%)$ & $130(81.7 \%)$ & $29(18.2 \%)$ \\
\hline & $\mathrm{P}=0.25$ & & $\mathrm{P}=0.81$ & & & $\mathrm{P}=0.0499 *$ & & $\mathrm{P}=0.82$ & \\
\hline Stress & $122(76.7 \%)$ & $37(23.2 \%)$ & $13(8 \%)$ & $129(81 \%)$ & $17(11 \%)$ & $157(98.8)$ & $2(1.2 \%)$ & $130(82 \%)$ & $29(18 \%)$ \\
\hline & $\mathrm{P}=0.62$ & & $\mathrm{P}=.92$ & & & $\mathrm{P}=.91$ & & $\mathrm{P}=.48$ & \\
\hline Dieting & $123(77.3 \%)$ & $36(22.6 \%)$ & $12(7.54 \%)$ & $129(81 \%)$ & $17(11 \%)$ & $119(74.8 \%)$ & $40(25.1 \%)$ & $130(82 \%)$ & $29(18 \%)$ \\
\hline & $\mathrm{P}=0.99$ & & $\mathrm{P}=0.14$ & & & $\mathrm{P}=0.34$ & & $\mathrm{P}=0.55$ & \\
\hline
\end{tabular}

The above table elaborates on association of life style and menstrual disorders. Participants consuming junk food and doing yoga, $74.8 \%$ are changing less than 4 pads per day. About $77.3 \%$ had normal cycles. Participants with stress $76.7 \%$ had regular cycles and $98.8 \%$ had normal menstri=ual flow but $82 \%$ of them had dysmenorrhoea

Table 6: Assocation between lifestyle, PCOS \& hypothyroidism

\begin{tabular}{|c|c|c|c|c|}
\hline Lifestyle & \multicolumn{2}{|c|}{ PCOS } & \multicolumn{2}{c|}{ Hypothyroidism } \\
\hline & Yes & No & Yes & No \\
\hline Junk food & $58(36.4 \%)$ & $101(63.5 \%)$ & $125(78.6)$ & $34(21.4 \%)$ \\
\hline & $\mathrm{P}=0.001 * *$ & & $\mathrm{P}=0.047 *$ & \\
\hline Yoga & $101(63.5 \%)$ & $58(36.4 \%)$ & $125(78.6 \%)$ & $34(21.4 \%)$ \\
\hline & $\mathrm{P}=.60$ & & $\mathrm{P}=0.047$ & \\
\hline Stress & $58(36.4 \%)$ & $101(63.5 \%)$ & $124(77.9 \%)$ & $35(22 \%)$ \\
\hline & $\mathrm{P}=.11$ & & $\mathrm{P}=0.047 *$ & \\
\hline Dieting & $43(27 \%)$ & $114(70.6 \%)$ & $114(70.6 \%)$ & $45(28.3 \%)$ \\
\hline & $\mathrm{P}=0.83$ & & $\mathrm{P}=0.31$ & \\
\hline
\end{tabular}

States association between life style PCOS and hypothyroidism. There is significant correlation between consumption of junk food and incidence of PCOS $(\mathrm{p}=0.001)$ and hypothyroidism $(\mathrm{p}=0.047)$. Strees is significantly correlated with hypothyroidism $(\mathrm{p}=0.047 \%)$ but not so with PCO $(\mathrm{p}=0.11)$

\section{Discussion}

The mean age of participants was $24.68+-2.07$ years. The present study showed mean age of menarche was $12.10+/-$ 1.22 years. which suites to Indian standard reported by different geographical area of India and other parts of world. $12.5+/-1.52$ years $(5) ; 12.6+/-1(24) 12.5$ years (23);13.9+/- 1.8 years (25).13.57+/-1.23 years (8), 14.2 years $(9)$; $12.4+/-$ years (23). Genetic configuration, environmental and socio economic factors and general health are contributing factors for age of menarche. In Medical college, $87 \%$ students were from urban area (As the study was conducted in medical college) and $86.7 \%$ were unmarried.

In present study, although high number of students $(82 \%)$ were having junk food atleast once in a week, no significant association was found with menstrual irregularity and food habits(veg \& non veg). Similar finding have been noticed in previous studies. ${ }^{7}$ The present study also found significant correlation of junk food with PCOS $(\mathrm{P}=0.001)$ Association of high BMI and junk food has been proved. This correlates with our finding.
Dysmenorrhoea and premenstrual symptoms are the common disorder that affects more than $50 \%$ of the menstruating women. The proposed cause of pain is

dysmenorrhoea is excess production of prostaglandins (PG) in the endometrial during the ovulatory cycle. It was shown that women with dysmenorrhoea have higher levels of PG in their plasma and menstrual discharge that women without dysmenorrhoea. Pre-menstrual symptoms are experienced prior to menstruation due to changes in blood levels of estrogens as well as progesterone. although high number of students $(82 \%)$ were having junk food at least once in a week. High number (82\%) of students has dysmenorrhoea but its association with junk food is not correlated in present study. This finding is contradictory to other studies which dysmenorrhoea and premenstrual symptoms (PMS) is common in junk food eaters. ${ }^{7}$

Jennifer Oates, $\mathrm{PhD}$, King's College London, U.K., assessed the evidence from 15 published studies on the effects of yoga practice on problems such as amenorrhea, oligomenorrhea, dysmenorrhoea, premenstrual syndrome, and premenstrual dysphoric disorder. They reported that enhanced mood, reduced pain, increased wellbeing, and a heightened relaxation response among the improved 
outcomes reported by women who participated in a yoga intervention, as reported in the article entitled "The Effect of Yoga on Menstrual Disorders: A Systematic Review." In present study $41.4 \%$ students were doing yoga regularly. The significant association with amount of flow has been found in our study. Students have high percentage of normal flow. $(\mathrm{P}=0.0495)$ though there was no any correlation with improvement of dysmenorrhoea. Some studies showed that students doing regular physical activity have less menstrual abnormalities. $^{21}$

Medical students have stressful life and menstruation related disorders commonly. ${ }^{4,6,8}$ Bogdan $\mathrm{F}$ covaliu et al observed that there is statistically significant association of low intensity stress with the severity of abnormal uterine bleeding,. As the stress level increases, there is higher intensity of back pain, joint and muscle pain. ${ }^{20}$ About $85.5 \%$ students were experiencing stress which was quite high. Psychological stress activates hypothalamo pituitary adrenal axis resulting in increased cortisol levels which is related to functional menstrual disorders. Cortisol increases brain function and slows other non essential body functions such as cellular growth, digestion and reproduction (Kalantroid et al 2004). Consequently synthesis and metabolism of gonadotrophins and estrogens are suppressed (Constantine et al 2002) that disturbs in menstrual cycle. In present study no significant association have been found with menstrual irregularities though we have not categorised stress by any standard questionnaire. Study conducted in malasya does not show any association between stress levels and menses patterns. ${ }^{17}$ Similar findings were reported by Clarvit. In her study, she found that there was no association between perceived stress and menstrual problem. Some studies showed strong association between two, ${ }^{9}$ On the contrary, other studies reported that stress score is a predictor for irregular menstrual cycle. ${ }^{17}$

About 54\% students were addicted to either tea or coffee which might be associated with increased stress. This is one of the ways to cope with stressful situation. It may include tea, coffee addiction and overeating. Stressful life events with poor coping skills may impact risk of addiction through increasing impulsive responding and self medication though it may not be possible to eliminate the stress through addiction. Stress is the key factor in addiction initiation, maintenance and relapse and thus failure for deaddiction. ${ }^{15}$ This controlled activation of the HPA axis may result in the production of an internal state of arousal or stimulation that is actually sought by the individual (i.e., the sensation-seeking hypothesis). ${ }^{16}$

In our study $81 \%$ have average duration of flow \& $74.8 \%$ had to change (2 pads per day) which has positive correlation with yoga. According to Begum et al $100(57.5 \%)$ respondents have average, menstrual flow while $>2(43.4 \%)$ had scanty and $2(1 \%)$ had heavy flow.

No significant association was found with irregular cycles $(30 \%)$ and menorrhagia $(1.25 \%)$ in the quantity with yoga in present study though we found scanty menses and irregular cycles in $74.8 \%$ of our study group. We also found hypothyroidism in $21.3 \%$ participants which quite high. The association might be because of high incidence of PCOS. In present study we have found significantly less incidence of menorrhagia in participants who are practising yoga and consuming junk food. $(\mathrm{p}=0.0499 \& \mathrm{p}=0.031)$.

In present study $21.3 \%$ were having hypothyroidism which is quite high, $32.7 \%$ had done their thyroid function test. The correlation between thyroid disorders and menstrual problems are well known. This coincides with the study conducted by Nangia Sangita Ajmani, et al $^{18}$ In present study we have found statistically significant correlation between hypothyroidism and junk food eaters and also students doing yoga significantly had less chances of hypothyroidism. $(\mathrm{p}=0.047)$

Research suggests that selenium deficiency may be linked to developing Hashimoto's thyroiditis and hypothyroidism. ${ }^{22}$ Some goiterogenic food like Chinese cabbage, cauliflower which are used in junk food like Manchurian are consumed more by students. The present study findings support this association.

\section{Conclusion}

The present study demonstrates that there is no any significant association between academic stress and menstrual disorder. Though we found yoga have a positive impact over menstrual flow. It improves menstrual flow. There is significant correlation of junk foods with PCOS and hypothyroidism in the medical colleges the education regarding physical, social and mental health should be given to the students. Though menstruation is a normal physiological phenomenon, some minor ailments can occur. These can lead to severe health issues like polycystic ovarian disease, obesity, psychological issues, and absenteeism in the college. The medical colleges should make committee for early detection of students with psychosocial as well as menstrual problems. The students identified should be provided psychological support and gynaecological counselling and life style modification like physical activity in the form of yoga, meditation to relieve the stress, sports activities promotion and making the campus junk food free in order to prevent further complications.

\section{Conflict of Interest: None.}

\section{References}

1. Narayan KA, Srinivasa DK, Pelto PJ, Veerammal S; Puberty rituals, reproductive knowledge and health of adolescent schoolgirls in South India. Asia Pac Popul J 2001;16(2): 22538 .

2. Singh A, Kiran D, Singh H, Nel B, Singh P, Tiwari P et al. Prevalence and severity of dysmennorhea: A problem related to menstruation among first and second year female medcal students. Indian J Physiol Pharmacol 2008;52(4): 389-97.

3. Sood M, Devi A, Azlinawati, Daher AM, Razali S, Nawawi H et al.; Poor correlation of stress levels and menstrual patterns among medical students. J Asian Behav Stud 2012;2(7):59-66

4. Hertweck P, Yoost J.Common problems in pediatric and adolescent gynecology. Expert Rev Obstet Gynecol 2010;5:311 
5. Amu EO, Bamidele JO. Prevalence of menstrual disorders among adolescent girls in osogbo, South Western Nigeria. Int $J$ Adolesc Med Health 2014;26:4:49-53

6. Karout N, Hawai SM, Altuwaijri S. Prevalence and pattern of menstrual disorders among Lebanese nursing students. East Mediterr Health $J$ 2012;18:346-52.

7. Anandha Lakshmi S, Saraswathi I, Saravanan A. Ramamchandran C. Prevalence of premenstruak syndrome and dysmennorhea among female medical students and its association with college absenteeism. Int J Biol Med Res 2011;2:1011-16

8. Liu Y, Gold EB, Lasley BL, Johnson WO. Factors affecting menstrual cycle characteristics. Am J Epidemiol 2004;160:13140.

9. 9)EKpenyong Ce, Davis KJ, Akpan UP, Daniel NE. Academic stress and menstrual disorders among female undergraduates in Uyo, South Eastern Nigeria-the need for health education. Niger J Physiol Sci 2011;26:193-198.

10. 10)Zhou M, Wege N, Gu H, Shang L, Li J, Siegrist J et al. Work and family stress is associated with menstrual disorders but not with fibrocystic changes: cross-sectional findings in Chinese working women. J Occup Health 2010;52:361-366.

11. 11)Nisar N, Zehra N, Haider G, Munir AA, Sohoo NA. Frequency, intensity and impact of premenstrual syndrome in medical students. J Coll Physicians Surg Pak 2008;18:481484.

12. 12)Issa BA, Yussuf AD, Olatinwo AW, Ighodalo $\mathrm{M}$. Premenstrual dysphoric disorder among medical students of a Nigerian university. Ann Afrr Med 2010;9:118-122.

13. Saipanish R. Stress among medical students in a Thai medical school. Med Teach 2003;25:502-506.

14. Stress as risk factor for menstrual disorders (Bogdan F.Covaliu,Norina Predescu, Sebastian M. Armean, Costin Minoiu
15. Stress and Addiction | Psychology Today https://www.psychologytoday.com/us/blog/sciencechoice/.../stress-and-addiction

16. The impact of strees on addiction European Neuropsychopharmacology vol 13 Issue December 2003, 435441

17. Savoy Homann, Mini Sood AMbigga Devi, Azlinawati, Aqil Mohd Daher, SAlmi Razali Hapizah Nawawi, Sareena \& Hashim Mohd Tahir et al. Menses and strees related changes in female medical students. 2011.

18. Nangia Sangita Ajmani, Vinita Sarbhai, Namrta Yadav, Mohini Paul, Ayesha Ahmad, and A. K. Ajmani. Role of Thyroid Dysfunction in Patients with Menstrual Disorders in Tertiary Care Center of Walled City of Delhi. J Obstet Gynaecol India 2016;66(2):115-119.

19. Can Yoga Reduce Symptoms of Menstrual Disorder? Neuroscience News April 27, 2017 Yoga can reduce pain and enhance mood for women suffering from a range of menstrual disorders, a new study reports. http://www.hvm.bioflux.com.ro/docs/2017.6-10.pdf

20. https://www.academia.edu/.../ISSN_2347954X_Print_A_Study_of_Menstrual_Disord...

21. https://www.verywellhealth.com/iodine-and-the-thyroid3231870

22. https://www.ncbi.nlm.nih.gov/pmc/articles/PMC3972521/

23. https://www.ncbi.nlm.nih.gov/pubmed/19786516

24. https://www.ncbi.nlm.nih.gov/pubmed/1911587

How to cite this article: Desai SS, Gohil P, Desai M, Sawant VD, To study the impact of lifestyle over menstrual pattern in medical students. Indian J Obstet Gynecol Res 2019;6(2):159-164. 